\title{
Stroke among Children with Sickle Cell Anemia in Mulago Hospital, Uganda
}

Munube $D^{1}$, Lwabi $P^{2}$, Ndeezi G1 ${ }^{1}$ Katabira $E^{3}$, Mukasa $\mathbf{M K}^{3}$, J oloba $\mathbf{M}^{4}$, Lhatoo $\mathrm{S}^{5}$, Sajatovic $\mathbf{M}^{6}$ and Tumwine $\mathrm{J} \mathrm{K}^{1}$

${ }^{1}$ Department of Pediatrics and Child Health, School of Medicine, College of Health Sciences, Makerere University, Kampala, Uganda

${ }^{2}$ Uganda Heart Institute, Mulago Hospital, Kampala, Uganda

${ }^{3}$ Department of Internal Medicine, School of Medicine, College of Health Sciences, Makerere University, Kampala, Uganda

${ }^{4}$ Deparment of Microbiology, School of Biomedical Sciences, College of Health Sciences, Makerere

University, Kampala, Uganda

${ }^{5}$ Department of Neurology, University Hospitals - Case

Medical Centre, Cleveland, USA

${ }^{6}$ Neurological and Behavioral Outcomes Centre,

University Hospitals - Case Medical Centre, Cleveland, USA

*Corresponding author: Deogratias Munube, Department of Pediatrics and Child Health, School of Medicine, College of Health Sciences, Makerere University, Kampala, Uganda

Received: April 13, 2017; Accepted: May 15, 2017; Published: May 22, 2017

\begin{abstract}
Background: Sickle Cell Anemia (SCA) is a leading cause of child morbidity and mortality affecting $4 \%$ of all newborns in Uganda. Stroke is a serious complication of SCA in childhood and $10 \%$ of patients with SCA will have had a stroke by the age of 20 years. Hitherto there has been limited information on SCA stroke in Uganda.
\end{abstract}

Objective: To describe the clinical presentation of children with SCA stroke; and hematological indices and interventions in those with a stroke.

Method: We studied 46 SCA children aged 2-18 years attending the sickle cell services of Mulago Hospital in Uganda from February to June 2011. Numerical data was summarized into mean $+/$ - standard deviation for normally distributed variables and ranges +/- inter-quartile range for skewed data. Categorical data was summarized into percentages.

Results: Forty six SCA children with stroke are described in this case series. The median age at first stroke was 4 years [Inter-quartile range (IQR) 2-6]. Symptoms of children with SCA stroke included behavior changes, headache and seizures. Findings on physical examination included hemiplegia, aphasia, and limb ataxia. Four of the 46 children with SCA stroke had a sickle cell hemoglobin $(\mathrm{HbS})<30 \%$. Ninety five percent $(44 / 46)$ of the children had received a blood transfusion.

Conclusion: Children with stroke in sickle cell anemia presented with a range of neurological symptoms and signs. Further research is needed to determine the risk factors for stroke in our population.

Keywords: Sickle Cell Anemia; Stroke; Children; Uganda

\section{Introduction}

Sickle Cell Anemia (SCA) is a common genetic condition due to a hemoglobin disorder in which there is inheritance of mutant hemoglobin genes from both parents [1]. It is the commonest inheritable disease in Africa [2]. In Uganda it is a leading cause of child morbidity and mortality affecting $4 \%$ of all newborns [3]. Stroke is a leading cause of mortality in SCA and approximately $10 \%$ of patients in North America will have had a stroke by the age of 20 years [4]. Stroke in patients with SCA involves large vessels in the arterial circulation. The internal carotid and the middle cerebral arteries are particularly affected and may present as cerebral infarction or hemorrhage [5]

The risk of stroke is highest during the first decade especially in children aged 2 to 5 years [4]. The risk is lowest before the age of 2 years, probably because of the protection, against sickling, accorded by fetal hemoglobin $[4,5]$. It has now been established that a child with SCA has a stroke risk that is 300 times more than that of a child without SCA $[4,5]$.

While stroke complicating SCA has been reported from several studies in Nigeria, Cameroun and Kenya [6,7], it has not been reported from Uganda.

In this study, we describe the clinical features of children with
SCA who had suffered a stroke attending Mulago Hospital, Uganda's National Referral Hospital.

\section{Methods}

In this case series, we describe the SCA children who suffered a stroke. In this study, Stroke was defined using the World Health Organization definition of stroke: "rapidly developing clinical signs of focal (or global) disturbance of cerebral function, with symptoms lasting 24 hours or longer or leading to death with no apparent cause other than of vascular origin [8]. The study was carried out in the Sickle Cell Clinic and Pediatrics wards of Mulago Hospital, in Kampala, Uganda from February to June 2011. The Sickle Cell Clinic has 12,000 registered patients, with an average monthly attendance of 600 and an average daily attendance of 30-40 patients. The clinic runs daily from Monday to Friday. The study investigators recruited, and performed physical examinations among the study participants. A sample of whole blood was collected from the study participants using aseptic techniques during the study period.

An inclusion criterion for this study was children aged 2 to 18 years with a confirmed diagnosis of sickle cell anemia and clinical diagnosis of stroke. For those who presented with an initial stroke without a prior diagnosis of SCA, a hemoglobin electrophoresis was done to confirm sickle cell disease and provided written informed 
consent to participate in the study.

Sickle cell anemia children who presented with a stroke to the Sickle cell clinic were admitted to the Pediatrics wards of Mulago Hospital for management. Consent from caretakers and assent for children aged 8 to 18 years.

\section{Procedures}

Blood pressure (BP): The patient's blood pressures were taken three times. The second and third reading was averaged to compute the patients reading. This was done using an aneroid BP machine, Fazzini, Italy with multiple child size cuffs. In this study high blood pressure was defined as a systolic BP and/or diastolic BP that is on repeated measurement, at/or above the $95^{\text {th }}$ percentile [9].

Oxygen saturation $\left(\mathrm{SPO}_{2}\right)$ : The patients $\mathrm{SPO}_{2}$ was determined using a Nellcor ${ }^{\mathrm{ma}} \mathrm{N} 65$ portable pulse oximeter. The reading was determined after the probe was kept on the patients' finger for more than 1 minute.

Laboratory investigations: A complete blood count $(\mathrm{CBC})$ was done using a Beckman Coulter CBC 5 Haemolyser, Beckman Coulter Inc., California, and USA. The hemoglobin electrophoresis was done using a Minicap Sebia Electrophoresis Machine, Sebia Inc., Georgia, and USA in order to verify the diagnosis of SCA in the children in the study. In addition, the level of $\mathrm{HbF}$ and $\mathrm{HbS}$ were also determined.

\section{Statistical analysis}

All data was recorded in structured questionnaires that were developed by the investigators. It included questions about the child's current state of well being and any interventions the child may have received, This structured questionnaire was entered into a statistical software package EPI-DATA Version 3.1, (Epi-data Association, Odense, Denmark) and examined for completeness, consistency, and accuracy. The data was exported to STATA Version 10, (Stata Corp, Texas, and USA) for analysis.

The participants were recruited over a four month period from February to June 2011. They were recruited from both the SCC and the Hematology ward of Mulago Hospital.

Numerical data were summarized into means, and standard deviation for normally distributed variables; or medians and interquartile ranges for skewed data. For some continous data, we categorized them to be able to describe possible risk factors associated with stroke in our study participants.

\section{Ethics and Consent}

Permission to carry out the study was obtained from the Department of Pediatrics and Child Health; Makerere University College of Health Sciences, School of Medicine Research and Ethics Committees (SOMREC). Written informed consent was obtained from the caregivers/parents of eligible children. In addition, assent was obtained from children aged 8 years to 18 years before enrollment.

\section{Results}

We recruited 46 children with SCA stroke between February and June 2011. Forty six of these had sickle cell anemia with stroke. There were 23 (50\%) males and 23 (50\%) females. The median age for with SCA-related stroke was 4 years (inter-quartile range 5 to 11 ) years.
Table 1: Baseline characteristics of children with sickle cell anemia stroke.

\begin{tabular}{|c|c|}
\hline Variable & $\begin{array}{c}\text { Stroke } \\
\mathrm{N}=46(\%)\end{array}$ \\
\hline \multicolumn{2}{|l|}{ Age (years) } \\
\hline$<5$ & $10(21.7)$ \\
\hline$>5-18$ & $36(79.3)$ \\
\hline Gender (Males) & $23(50)$ \\
\hline \multicolumn{2}{|l|}{ Tribe } \\
\hline Ganda & $32(70)$ \\
\hline Others & $14(30)$ \\
\hline \multicolumn{2}{|l|}{ Admitted to hospital } \\
\hline Type of visit & $46(100)$ \\
\hline Sickle cell day care clinic visit & $40(87)$ \\
\hline Hospital admission & $6(13)$ \\
\hline Sibling with SCA related Stroke & 9 (19.6) \\
\hline
\end{tabular}

$\mathrm{N}=$ number of children.

Table 2: Symptoms at presentation of sickle cell anemia children with stroke.

\begin{tabular}{|l|c|}
\hline Variable & Stroke \\
\hline (history) & N=46 (\%) \\
\hline Fever & $24(51)$ \\
\hline Headache & $8(18.8)$ \\
\hline Chest pain & $6(13.3)$ \\
\hline Cough <2 weeks & $24(51)$ \\
\hline Difficulty in breathing & $8(15.5)$ \\
\hline Limb or bone pains & $20(44.4)$ \\
\hline Abdominal pain & $21(47.7)$ \\
\hline Joint pain & $13(29.5)$ \\
\hline Jaundice & $21(46.7)$ \\
\hline Stroke & \\
\hline Primary stroke & $29(63.0)$ \\
\hline Recurrent stroke & $17(27.0)$ \\
\hline
\end{tabular}

$\mathrm{N}$ : Number of children.

The age distribution showed a peak of 6 years with $35 \%$ of the children below five years of age. The rest of the baseline characteristics of the children are shown in Table 1.

\section{Clinical characteristics of study participants with SCA stroke}

History: this was collected by the investigators from the structured questionnaires.

Most of patients presented with a history of fever (51\%) and cough $<2$ weeks $(51 \%)$. There were no other major symptoms noted in the children with sickle cell anemia related stroke. The remaining findings are shown in Table 2.

Examination: this was collected by the investigators who performed the clinical examinations of the study participants.

General and other systems: Most children with stroke had low oxygen saturation (58.7\%), while $43.5 \%$ had high blood pressure. The remaining findings are shown in Table 3. 
Table 3: Signs at presentation of children with sickle cell anemia stroke.

\begin{tabular}{|l|c|}
\hline Variable & Stroke $\mathbf{N}=\mathbf{4 6}(\%)$ \\
\hline Severe pallor $(\mathrm{Hb}<5 \mathrm{~g} / \mathrm{dl})$ & $1(2.2)$ \\
\hline Jaundice & $21(46.7)$ \\
\hline Temperature $\left(>37.5^{\circ} \mathrm{C}\right)$ & $8(17.4)$ \\
\hline Bone tenderness $(\mathrm{Yes})$ & $20(43.5)$ \\
\hline Crepitations & $1(2.2)$ \\
\hline Chest in-drawing & $1(2.2)$ \\
\hline Hepatomegaly & $7(15.2)$ \\
\hline Splenomegaly & $0(0)$ \\
\hline
\end{tabular}

$\mathrm{N}$ : Number of children, $\mathrm{Hb}$ : Haemoglobin.

Table 4: Hematological indices in children with sickle cell anemia stroke.

\begin{tabular}{|c|c|}
\hline \multirow{2}{*}{ Variable } & Stroke \\
\hline & $\mathrm{N}=46(\%)$ \\
\hline \multicolumn{2}{|l|}{ Anaemia (g/dl) } \\
\hline Severe anaemia $(\mathrm{Hb}<5 \mathrm{~g} / \mathrm{dl})$ & $1(2.2)$ \\
\hline No severe anaemia & $45(97.8)$ \\
\hline \multicolumn{2}{|l|}{ Steady state ( $g / d l)$} \\
\hline $\mathrm{Hb}<7$ & $9(19.6)$ \\
\hline $\mathrm{Hb}>$ or $=7$ & $37(80.4)$ \\
\hline \multicolumn{2}{|l|}{ HbS level (\%) } \\
\hline$<=30$ & $4(8.7)$ \\
\hline$>30$ & 42(91.3) \\
\hline \multicolumn{2}{|l|}{ HbF Level (\%) } \\
\hline$<15$ & $40(87)$ \\
\hline$>=15$ & $6(13)$ \\
\hline \multicolumn{2}{|c|}{ WBC Total count (leucocytosis) } \\
\hline WBC $>20,000$ & 14(30.4) \\
\hline WBC $<=20,000$ & $32(69.6)$ \\
\hline \multicolumn{2}{|l|}{$\begin{array}{l}\text { Platelet count } \\
\text { (thrombocytopenia) }\end{array}$} \\
\hline Plt $<=150$ & $1(2.2)$ \\
\hline Plt $>150$ & $45(97.8)$ \\
\hline \multicolumn{2}{|l|}{ Platelet count (thrombocytosis) } \\
\hline Plt $>400$ & 28(60.9) \\
\hline Plt $<=400$ & 18(39.1) \\
\hline
\end{tabular}

Hb: Haemoglobin, WBC: white blood cells, Plt: platelets.

Neurological findings: One in three children (32.6\%) with SCA stroke presented with a history of behaviour disturbance, while $21.7 \%$ had seizures. The care givers described these behavior abnormalities as: "laughing without stimulus", "screaming", "and abnormal movement of the head and neck", "lack of sleep". Other neurological symptoms included headache (17.4\%), confusion (17.4\%), visual and hearing loss (6.5\% respectively).

Neurological examination: The majority of children with SCA stroke presented with a motor deficit. Of the 46 children with stroke, hemiplegia $-80.4 \%$ (37) was the most prevalent deficit. Only $11.6 \%$ [5] presented with monoplegia and 9\% [4] presented with quadriplegia. Other neurological findings included limb ataxia (34.8\%), facial nerve
Table 5: Intervention received by sickle cell anemia children with STROKE.

\begin{tabular}{|c|c|}
\hline \multirow{2}{*}{ Variable } & STROKE \\
\hline & $N=46(\%)$ \\
\hline \multicolumn{2}{|c|}{ Malaria prophylaxis } \\
\hline Yes & $43(93.5)$ \\
\hline No & $3(6.5)$ \\
\hline \multicolumn{2}{|c|}{ Pneumococcal vaccine use } \\
\hline Yes & $4(8.7)$ \\
\hline No & 42(91.3) \\
\hline \multicolumn{2}{|c|}{ Hydroxyurea Use } \\
\hline Yes & $4(8.7)$ \\
\hline No & 42(91.3) \\
\hline \multicolumn{2}{|c|}{ Ever received blood transfusion } \\
\hline Yes & $44(95.7)$ \\
\hline No & $2(4.3)$ \\
\hline \multicolumn{2}{|c|}{ Number of blood transfusions } \\
\hline$>1$ & $33(71.7)$ \\
\hline $0-1^{1}$ & $13(28.3)$ \\
\hline
\end{tabular}

$\mathrm{N}$ : Number of children.

palsy (23.9\%), speech deficit and dysathria (26.1\%) respectively.

Haematological indices: Children with SCA stroke had lower levels of $\mathrm{HbS}<30 \%$ (8.7\%). In addition, children with stroke $(80.4 \%)$ had a higher steady state hemoglobin level of $\geq 7 \mathrm{~g} / \mathrm{dl}$. The rest of the indices are shown in Table 4.

Interventions in SCA stroke children: The children with sickle cell anemia related stroke were more likely to receive blood transfusion $(95.7 \%)$. The rest of the interventions in the stroke patients are shown in Table 5.

\section{Discussion}

In this paper, we describe the clinical presentation of children with SCA stroke and their hematological indices. We have also described interventions in these same children.

\section{Clinical presentation of children with cerebrovascular accident}

Most of the patients with stroke presented with a history of change in behavior, seizures, headache, confusion and weakness of the limbs. A history of change in behaviour was recorded in a third of our patients with SCA stroke. Some studies have described mental status changes in children who present with stroke [13]. In our study, seizures were reported in one out of five children with SCA stroke. This finding is similar to what Kehinde and others have reported from Nigeria. It's however much lower than the 55\% reported by George and Frank-Briggs also from Nigeria [14]. The pathophysiology of seizures in stroke is unclear but it has been postulated that vasculopathy which is associated with SCA may be a key factor in seizure development $[14,15]$.

Headache was reported in one in five children with SCA stroke. Again this is similar to findings by Kehinde who found that $24 \%$ of stroke patients presented with a headache [13]. However studies 
from Saudi Arabia by Zakaria and others found a lower prevalence of headache of one in nine children with SCA stroke [12].

Confusion was similarly reported in one in five children with SCA stroke in our study. This finding was much higher than was reported in a Jamaican cohort of SCA children where the prevalence was only $6 \%$. The mechanism of confusion in SCA stroke is not known but it has been associated with severe bacterial infection and vaso-occlusive crisis $[16,17]$. In this study, we did not look for evidence of severe bacterial infection.

Other complaints associated with stroke included loss of sight and hearing. In this study, these occurred in 1 out of 16 children. This was similar to findings from a large cohort study done in Lagos, Nigeria [14]. The cause of loss of sight and hearing is possibly due to ischemia from vascular occlusions [15,18].

\section{Motor deficits}

Hemiplegia was the commonest clinical sign presenting in four out of five children with SCA stroke. This finding is similar to what other studies in Jamaica [16] and Saudi Arabia [12] had found. However, one study in Nigeria found that hemiplegia was present in half the children with SCA-related stroke [14]. This was much lower than what we found in the current study. Hemiplegia is thought to be due to ischemia from large cerebral artery occlusion as a result of the sickle cells and it could also result from of hemorrhage [15,19].

In our study monoplegia was recorded in 1 in 10 of children with SCA stroke. This was higher than what was reported in a natural history of stroke study by Powars and others [19]. Monoplegia may be due to occlusion of the blood vessels that supply the brachial plexus [15].

Quadriplegia occurred in one out of ten children with SCArelated stroke. Similar findings were reported by Powars and others in California [21]. All our quadriplegic patients had recurrent stroke. This finding is similar to what has been reported elsewhere [21]. Patients with quadriplegia have had both right and left hemiplegia with brain CT scans showing bilateral low density areas indicative of injury of the cerebral tissues [4].

\section{Other neurological signs}

Speech deficit (aphasia): In this study speech deficit (aphasia) occurred in one in five children with SCA stroke. This is higher than what Saudi [12] and Nigerian [14] authors have reported. Our prevalence of speech deficits was lower than what was reported in the USA, and Jamaica $[4,16]$.

Limb ataxia: Limb ataxia was the second commonest neurological finding in our study. It affected one in three children. This was much higher than that reported by Powars and others. Limb ataxia results from a dysfunction in the cerebellum and can be a result of stroke which leads to poor control of movements of the limbs $[4,19,20]$.

Facial nerve palsy: Facial nerve palsy occurred in one in five of our SCA stroke patients. This is higher than what has been reported from the USA and Nigeria [14,20]. Cranial nerve palsies do occur as a result of occlusion of the major cerebral artery. In children with SCA stroke facial nerve palsies may be due to occlusion of the same vessel.

Lung crepitations: We found that a larger proportion of children with stroke had crepitations in their lungs. This was not surprising finding because several studies have shown a direct correlation between lung infections. In children with acute chest syndrome (ACS), the risk for stroke is higher compared to a child without ACS [21]. This finding does advance the pathophysiology of stroke in children with sickle cell anemia. The presence of a lung infection does predispose the child to hypoxia. This triggers a cascade of sickling and leads to worsening of the oxygenation of the lungs [21]. High Blood pressure more likely to have a high blood pressure. This was similar to studies by Ohene-Frempong in the USA and by Balkaran in Jamaica $[4,16,19]$. However, the blood pressure readings were taken after the occurrence of the primary outcome of this study. It is therefore, difficult to attribute the high blood pressure as a predictor for stroke in these children.

Hepatomegaly: Hepatomegaly is a common clinical finding in children with sickle cell anemia as a result of chronic haemolysis. We found that children with stroke were about four times more likely to have an enlarged liver as compared to those without a stroke. The association between stroke and hepatomegaly has not been described elsewhere. This finding does suggest that hepatomegally can be used as a marker for severity of illness in children with sickle cell anaemia [22]. However, there is no biological explanation that explains the risk of stroke as a result of a hepatomegaly $[16,19]$.

Hematological indices: The children with SCA stroke are managed with chronic transfusions as standard of care to prevent recurrence of stroke by maintaining $\mathrm{HbS}$ levels below 30\% [23]. In our study, only 1 in 10 children with SCA stroke had an $\mathrm{HbS}<30 \%$. This was due to the poor follow up by patients in our clinic who live in various parts of the country. In addition it is the only sickle cell clinic in Uganda. This is a disturbing finding since we know that SCA children who's $\mathrm{HbS}$ are above $30 \%$ are at a risk of getting recurrent stroke In our comparative group no child had an $\mathrm{HbS}<30 \%$ thus putting all the children at a high risk for stroke.

\section{Interventions}

Hydroxyurea: Children with stroke were started on Hydroxyurea due to the complication. In our children with stroke, only 4 out 46 where started on Hydroxyurea. The role of Hydroxyurea in stroke prevention is based on its ability to induce $\mathrm{HbF}$ levels which subsequently reduce the HbS levels in children with SCA. Hydroxyurea as a medication in the prevention of primary stroke is still controversial [24]. Some studies support its use, while others have found no added advantage in its role in stroke prevention [25]. In our setting, no policy has been approved for Hydroxyurea use. However, some clinicians have introduced the medication for use in specific patients. These patients's are considered at a high risk for severe complications of SCA.

Blood transfusion: Children with SCA stroke received multiple blood transfusions.. This is because children with sickle cell anemia stroke receive multiple transfusions as their standard of care in the hospital. Chronic transfusion programs have been shown to prevent recurrence of stroke in children with sickle cell anemia [23]. In our setting, chronic transfusions programs are a challenge because of the inability of the caregivers to attend the clinic as regularly as suggested by the clinician. This puts our children with stroke at a future risk of recurrent stroke. 
Study limitations: This study had a number of limitations.

Recall bias by parents/caregiver/patient on description of symptoms prior to onset of stroke is a real issue. In order to reduce on this bias, we tried to limit the recall questions to three months.

Inability to screen the study participants using Trans-Cranial Doppler (TCD) ultrasound for cerebral vessel speeds. This was due to lack of local expertise in TCD screening.

Our inability to have CT or MRI scans for the children with stroke limited our ability to describe the areas affected in the brain. This was as a result of lack of funding.

\section{Conclusion}

We conclude that SCA patients with stroke presented commonly with: behaviour changes, headache and seizures; hemiplegia, aphasia and limb ataxia. Only a very small number of the SCA children, regardless of their stroke status, had $\mathrm{HbS}<30 \%$. Further research is needed to determine the risk factors for stroke in our population.

\section{References}

1. Sickle cell anaemia: report by the Secretariat. Geneva: World Health Organization; 2006.

2. Hendrickse RG, Barr DGD, Mathews TS. Disorder of the Blood, Pediatrics in the Tropics. London: Blackwell Scientific Publishers; 1991.

3. Serjeant GR, Ndugwa CM. Sickle cell disease in Uganda: a time for action East Afr Med J. 2003: 80: 384-387.

4. Ohene-Frempong K, Weiner SJ, Sleeper LA, Miller ST, Embury S, Moohr JW et al. Cerebrovascular accidents in sickle cell disease: rates and risk factors. Blood. 1998; 91: 288-294.

5. Verduzco LA, Nathan DG. Sickle cell disease and stroke. Blood. 2009; 114 5117-5125.

6. Njamnshi AK, Mbong EN, Wonkam A, Ongolo-Zogo P, Djientcheu VD, Sunjoh FL, et al. The epidemiology of stroke in sickle cell patients in Yaounde, Cameroon. J Neurol Sci. 2006; 250: 79-84.

7. Makani J. Stroke in sickle cell disease in Africa: case report. East Afr Med J. 2004; 81: 657-659.

8. The World Health Organization MONICA Project (monitoring trends and determinants in cardiovascular disease): a major international collaboration. WHO MONICA Project Principal Investigators. J Clin Epidemiol. 1988; 41: 105-114.

9. Falker B. The fourth report on the Diagnosis, evaluation and treatment of High blood pressure in children and adolescents. 2005.

10. Fleiss J, Levin, B. Cho Paik, M. Statistical Methods for Rates and Proportions. $3^{\text {rd }}$ ed. New York: John Wiley and Sons; 1981: 44-45.
11. Mpalampa L. Fetal hemoglobin and disease severity in sickle cell anemia patients attending the sickle cell clinic in Mulago Hospital. Kampala: Makerere University. 2010.

12. Al Hawsawi ZM, Ismail GA. Stroke among sickle cell disease patients in Madina Maternity and Children's Hospital. Ann Saudi Med. 1998; 18: 472474.

13. Kehinde MO, Temiye EO, Danesi MA. Neurological complications of sickle cell anemia in Nigerian Africans--a case-control study. J Natl Med Assoc. 2008; 100: 394-399.

14. George IO, Frank-Briggs Al. Stroke in Nigerain Children with Sickle Cell Anemia. Journal of Public Health and Epidemiology. 2011; 3: 407-409.

15. Switzer JA, Hess DC, Nichols FT, Adams RJ. Pathophysiology and treatment of stroke in sickle-cell disease: present and future. Lancet Neurol. 2006; 5: 501-512.

16. Balkaran B, Char G, Morris JS, Thomas PW, Serjeant BE, Serjeant GR. Stroke in a cohort of patients with homozygous sickle cell disease. J Pediatr. 1992; 120: 360-366.

17. Williams TN, Uyoga S, Macharia A, Ndila C, McAuley CF, Opi DH, et al. Bacteraemia in Kenyan children with sickle-cell anaemia: a retrospective cohort and case-control study. Lancet. 2009; 374: 1364-1370.

18. Stockman JA, Nigro MA, Mishkin MM, Oski FA. Occlusion of large cerebral vessels in sickle-cell anemia. N Engl J Med. 1972; 287: 846-849.

19. Powars D, Wilson B, Imbus C, Pegelow C, Allen J. The natural history of stroke in sickle cell disease. Am J Med. 1978; 65: 461-471.

20. Earley CJ, Kittner SJ, Feeser BR, Gardner J, Epstein A, Wozniak MA, et al. Stroke in children and sickle-cell disease: Baltimore-Washington Cooperative Young Stroke Study. Neurology. 1998; 51: 169-176.

21. Vichinsky EP, Neumayr LD, Earles AN, Williams R, Lennette ET, Dean D, et al. Causes and outcomes of the acute chest syndrome in sickle cell disease. National Acute Chest Syndrome Study Group. N Engl J Med. 2000; 342: 1855-1865.

22. Olatunji PO, Falusi AG. Persistent hepatomegaly: an index of severity in sickle cell anemia. East Afr Med J. 1994; 71: 742-744.

23. Adams RJ, McKie VC, Hsu L, Files B, Vichinsky E, Pegelow C, et al. Prevention of a first stroke by transfusions in children with sickle cell anemia and abnormal results on transcranial Doppler ultrasonography. N Engl J Med. 1998; 339: 5-11.

24. Ware RE, Zimmerman SA, Schultz WH. Hydroxyurea as an alternative to blood transfusions for the prevention of recurrent stroke in children with sickle cell disease. Blood. 1999; 94: 3022-3026.

25. Ware RE, Schultz WH, Yovetich N, Mortier NA, Alvarez O, and Hilliard L, et al. Stroke with Transfusions Changing to Hydroxyurea (SWiTCH): a phase III randomized clinical trial for treatment of children with sickle cell anemia, stroke, and iron overload. Pediatr Blood Cancer. 2011; 57: 1011-1017.
Austin Pediatr - Volume 4 Issue 2 - 2017

ISSN : 2381-8999 | www.austinpublishing group.com

Munube et al. (C) All rights are reserved
Citation: Munube D, Lwabi P, Ndeezi G, Katabira E, Mukasa MK, Joloba M, et al. Stroke among Children with Sickle Cell Anemia in Mulago Hospital, Uganda. Austin Pediatr. 2017; 4(2): 1055. 